\title{
Parálisis facial periférica bilateral como presentación inicial del síndrome de Guillain-Barré: informe de un caso
}

Bilateral facial nerve paralysis as initial manifestation of guillain-barré syndrome: a case report

Mario Alberto Lora Andosilla (1), Fanny Macia Brun (2), Carlos Arturo Cassiani Miranda (3), Rafael Ignacio Herrera (1), Marco Antonio Luján Agámez (4), Helí Hernández Ayazo (4)

\begin{abstract}
RESUMEN
El síndrome de Guillain-Barré (SGB) es un grupo heterogéneo de alteraciones neurológicas relacionadas que afectan los nervios periféricos del cuerpo. Generalmente se produce después de una infección aguda que favorece a la aparición de una respuesta autoinmune contra las moléculas de los gangliósidos de la mielina de los nervios periféricos. La parálisis facial periférica bilateral es una manifestación neurológica rara $(0,3 \%$ - $2 \%$ de los casos) y puede deberse a múltiples etiologías, entre las que se destaca el SGB. Se presenta el caso de un paciente de 39 años que consultó al servicio de urgencias del hospital Universitario del Caribe por parálisis facial bilateral asociada a deterioro motor progresivo y disautonomía. Se realizaron estudios que documentan SGB y se inicia manejo médico con inmunoglobulina intravenosa. El paciente presenta mejoría clínica notoria de su cuadro clínico y es dado de alta del hospital. La parálisis facial periférica bilateral es una entidad neurológica rara que puede asociarse con el síndrome de Guillain-Barré. Es necesario hacer el diagnóstico diferencial respecto de otras entidades clínicas que cursan con parálisis facial periférica bilateral. Se debe iniciar precozmente con inmunoglobulina intravenosa para aumentar la probabilidad de recuperación. El pronóstico es bueno en la mayoría de los casos.
\end{abstract}

PALABRAS CLAVE: Inmunoglobulina humana intravenosa, parálisis facial bilateral, plasmaféresis, síndrome de Guillain-Barré (DECS).

\section{SUMMARY}

Guillain-Barré syndrome (GBS) is a heterogeneous group of related neurological disorders that affect the peripheral nerves. Generally, it occurs after an acute infection that favors the occurrence of an autoimmune response against the myelin gangliosides molecules of the peripheral nerve. Bilateral peripheral facial nerve paralysis is a rare neurological symptom $(0.3 \%-2 \%$ of cases) and may be due to multiple etiologies; among which GBS emerge. The case of a 39 years old patient who consulted by bilateral facial nerve paralysis associated with progressive motor impairment and dysautonomia, is presented. Studies documented GBS. Subsequently, the patient presents successful improvement of his symptoms after intravenous immunoglobulin use and is discharged from the hospital. Bilateral peripheral facial palsy is a rare neurological condition that can be associated with Guillain-Barre syndrome. It is necessary to make the differential diagnosis with other clinical entities presenting with bilateral facial palsy. Intravenous inmunoglbulin should be initiated early to increase the probability of recovery. The prognosis is good in most cases.

KEY WORDS. Bilateral facial nerve paralysis, Guillain-Barré syndrome, intravenous immunoglobulin, plasmapheresis $(\mathrm{MeSH})$.

(1) Estudiante de posgrado en Medicina Interna, Universidad de Cartagena.

(2) Médico General, Universidad del Sinú.

(3) Estudiante de posgrado en Psiquiatría, Universidad de Cartagena.

(4) Docente, Facultad de Medicina, Universidad de Cartagena.

Recibido: 17/08/15. Aceptado: 11/11/15.

Correspondencia: Mario Alberto Lora: mlora284@gmail.com 


\section{INTRODUCCIÓN}

El síndrome de Guillain-Barré es un grupo heterogéneo de alteraciones neurológicas relacionadas que afectan los nervios periféricos del cuerpo humano; en la mayoría de los casos presenta resolución espontánea y es mediado por un proceso autoinmune $(1,2)$. Generalmente lo precede un proceso infeccioso viral y/o bacteriano. El patrón de presentación clínica habitual es la debilidad muscular simétrica, progresiva y ascendente de los miembros inferiores, asociado a disminución o ausencia de reflejos osteotendinosos (3-6).

Sin embargo, existen otros patrones de presentación también descritos en la literatura médica, entre los que se encuentran ataxia, parestesia y debilidad bilateral de manos y pies, disautonomía (taquicardia, hipertensión alternando con hipotensión, diaforesis, etc.), parálisis facial periférica bilateral (6), con los cuales el clínico debe estar siempre familiarizado para hacer un diagnóstico y tratamiento oportunos.

La parálisis facial periférica bilateral es una manifestación neurológica rara que ocurre entre el 0,3-2\% de los pacientes $(6)$ y puede tener diversas causas $(1,2)$, entre las que se destacan: infecciones por virus, bacterias y espiroquetas (5).

Cuando se presenta una parálisis facial periférica bilateral, el síndrome de Guillian-Barré contribuye con más del $50 \%$ de los casos (6), aunque no es habitual que su forma de presentación inicial sea parálisis facial bilateral sin otra focalización neurológica $(2,7,8)$.

A continuación se describe un caso que ingresó al servicio de urgencias, cuyo debut fue parálisis facial periférica bilateral. Destacamos la importancia del reconocimiento clínico temprano junto al registro de los hallazgos típicos de laboratorio, medidas que permiten al clínico realizar un mejor abordaje diagnóstico y terapéutico, lo que finalmente se reflejará en una recuperación clínica favorable para los pacientes.

\section{Presentación del caso}

Se trata de un hombre de 39 años de edad, previamente sano, que manifestó cuadro clínico de tres días de evolución consistente en parestesias constantes de manos y pies asociadas a cefalea global punzante de leve a moderada intensidad. Por lo anterior, decide consultar a centro de cuidado primario donde fue valorado por médico general, quien solo encontró cifras tensionales elevadas (160/90 $\mathrm{mmHg}$ ), por lo que le da salida ambulatoria con enalapril $20 \mathrm{mg}$ vía oral cada doce horas y acetaminofén $500 \mathrm{mg}$ vía oral cada seis horas.

Al siguiente día en el paciente persiste la sintomatología $\mathrm{y}$ ahora, como dato adicional, presenta visión borrosa y diplopía. La noche antes de consultar al servicio de urgencias nota que "se le salen los líquidos muy fácilmente de la boca al tratar de ingerirlos, principalmente del lado derecho". Finalmente, por agudización de cefalea, a la que cataloga como "la peor cefalea de su vida", decide trasladarse al servicio de urgencias de un hospital de tercer nivel. Durante el traslado al hospital el paciente nota que va perdiendo progresivamente la fuerza muscular en todas las extremidades (al mismo tiempo), al punto de necesitar ayuda para salir del taxi que lo llevó. Durante la entrevista inicial con el médico de urgencias refirió, además de lo anotado, que veinte días antes había presentado cuadro respiratorio agudo de presunto origen viral, el cual se resolvió espontáneamente.

Al examen físico de ingreso se encuentra paciente consciente con cifras tensionales elevadas $(160 / 100 \mathrm{mmHg})$, taquicárdico (104 lpm), sin distrés respiratorio. Llama la atención una parálisis facial bilateral (Figura 1) con signo de Bell bilateral positivo (Figura 2). No se encontró rigidez de nuca, ni otra alteración al examen neurológico inicial, incluyendo reflejos osteotendinosos y marcha. Se inició manejo médico con cristaloides y analgesia endovenosa. Se ordena realizar inmediatamente tomografía computarizada de cerebro, que fue normal, pero por sospecha de hemorragia subaracnoidea se hizo punción lumbar, la cual mostró los hallazgos que aparecen en la Tabla 1 . Teniendo en cuenta los hallazgos clínicos de ingreso y los resultados de la punción lumbar (pleocitosis a expensas de linfocitos con aparición de hematíes en el LCR $-20 \%$ crenados- e hiperproteinorraquia), se adiciona al manejo aciclovir endovenoso y esteroide endovenoso (dexametasona), considerando como diagnóstico diferencial encefalitis viral. Se solicita realizar panangiografía cerebral para descartar

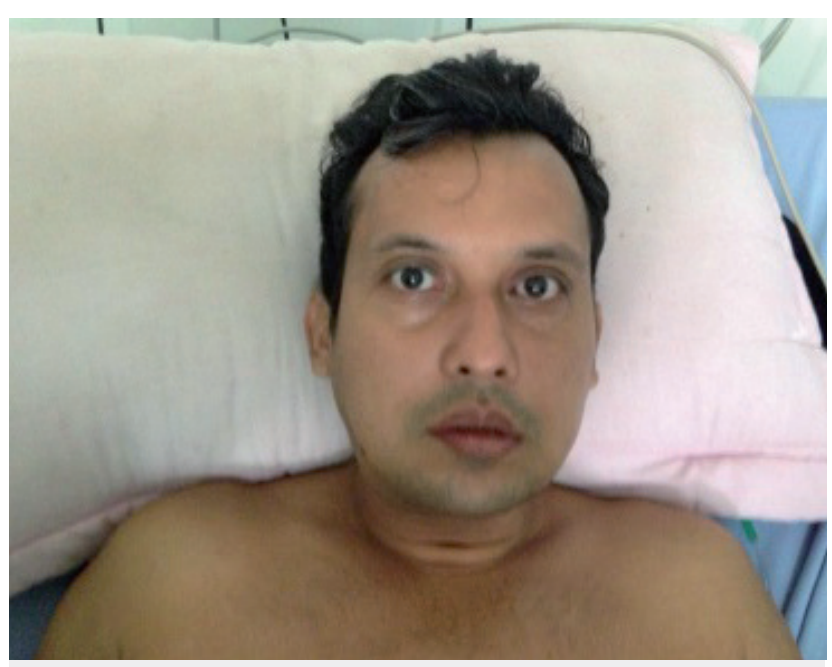

Figura 1. Evaluación clínica del séptimo par craneal. Nota: se observa incapacidad para fruncir el ceño y sonreír al mismo tiempo. 


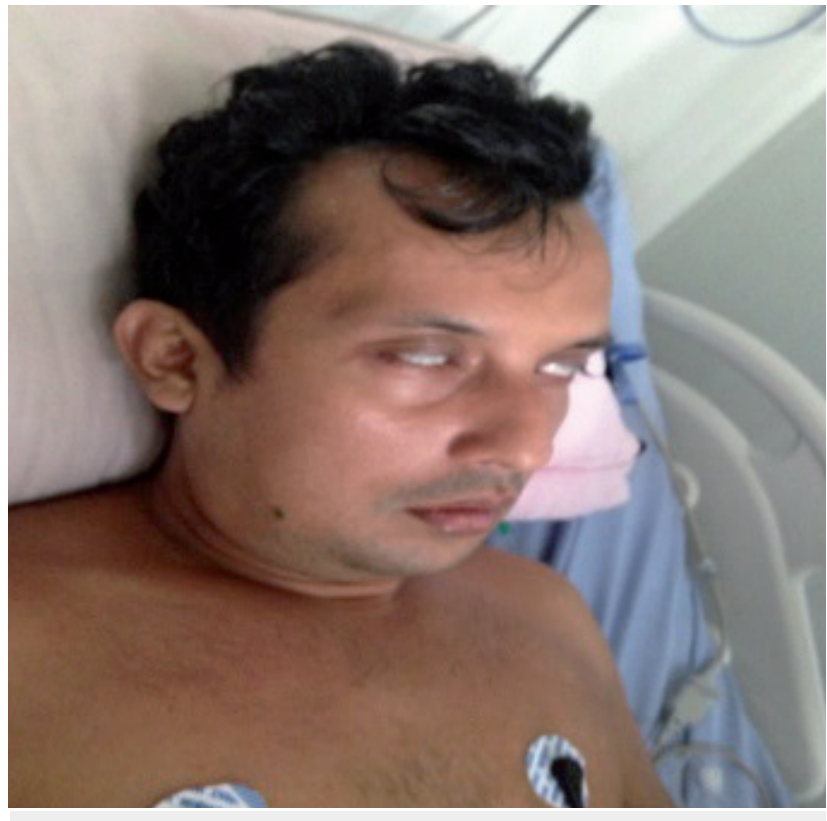

Figura 2. Signo de Bell bilateral positivo.

completamente hemorragia subaracnoidea. Se traslada al paciente a unidad de cuidados especiales, donde presenta una evolución estable, sin nuevo deterioro neurológico y se realiza panangiografía cerebral, que fue reportada como normal. Por buena evolución clínica hasta el momento y normalización de cifras tensionales, se ordena traslado a sala general.

Al cuarto día de su estancia hospitalaria el paciente persiste con parálisis facial periférica bilateral, pero ahora presenta como dato nuevo cuadriparesia flácida (fuerza muscular 3/5), asociada a arreflexia osteotendinosa en las cuatro extremidades. Se nota, además, labilidad de la presión arterial (hipotensión alternada con hipertensión arterial) y episodios de taquicardia sinusal sostenida. Se realiza "test de respiración única”, que resultó positivo (paciente contó hasta 18), por lo que se ordena traslado inmediato a unidad de cuidados intermedios dada la posibilidad de deterioro respiratorio agudo. Se solicitó además electromiografía de cuatro extremidades más medición de velocidad de conducción. Se ordenaron estudios para buscar presencia de microorganismos potencialmente causales como virus de Epstein-Barr, citomegalovirus, Borrelia burgdorferi, virus del herpes simple, VIH, VDRL, reportados como negativos. Se consideró realizar manejo médico con inmunoglobulina endovenosa pensando en la posibilidad diagnóstica de síndrome de Guillain-Barré. Se realizó electromiografía que mostró signos de compromiso axonomielínico de nervios periféricos; estos hallazgos, compatibles con polineurorradiculopatía de predominio axonal (síndrome de Guillain-
Tabla 1. Punción lumbar 1

\section{Citoquímico de LCR}

Color antes de centrifugar

Incoloro

Aspecto antes de centrifugar

Transparente

Color después de centrifugar

Incoloro

Aspecto después de centrifugar

Transparente con botón hemático

$\mathrm{pH}$

8,0

Presencia de coágulo

No

Examen citológico

Recuento total de leucocitos

Linfocitos

Neutrófilos

$70 \%$

$30 \%$

\section{Eritrocitos}

Recuento total

$100 / \mathrm{mm} 3$

Hematíes frescos

$80 \%$

Hematíes crenados

$20 \%$

Examen químico

Glucosa

$51 \mathrm{mg} / \mathrm{dl}$

Proteínas

$164,11 \mathrm{mg} / \mathrm{dl}$

$\mathrm{LDH}$

$35 \mathrm{U} / \mathrm{dl}$

Otros

Baciloscopia, $\mathrm{KOH}$, tinta china, VDRL, cultivo de LCR
Gram, no se observan gérmenes

Negativos

Barré) (Tabla 2). Se inició inmunoglobulina endovenosa $\neg$-IGIV- (400 mg/kg/día por cinco días), con lo que el paciente comienza a evolucionar satisfactoriamente, mejorando de modo notorio fuerza muscular en extremidades (retorna a un grado 5/5 en todas las extremidades). Se realiza nueva punción lumbar (Tabla 3) en el undécimo día de su hospitalización, la cual muestra disociación albuminocitológica, y se evidencia mejora de parálisis facial (Figura 3), por lo cual es dado de alta, evolucionando satisfactoriamente en su domicilio. En la actualidad realiza ejercicios de terapia física para rehabilitación de musculatura facial y controles por el servicio de Neurología (Figuras 4 y 5).

\section{DISCUSIÓN}

Charles Bell, en su estudio de la parálisis facial, fue el primero en describir un caso de parálisis facial bilateral ( 9 , 10). Sin embargo, a diferencia de la parálisis unilateral, que 
Tabla 2. Interpretación de electromiografía de miembros superiores e inferiores

EMG en reposo: silencio eléctrico sin signos de denervación actual.

Esfuerzo máximo: patrón de tipo interferencial en los músculos explorados.

Conducción nerviosa de miembros superiores e inferiores: se evidencia caída de la amplitud y bloqueo (incluyendo ausencia de onda F) de la conducción de nervios mediano, ulnar, peroneo y tibial bilateral.

Conclusiones: estudio de electromiografía de las cuatro extremidades, sin evidencia de alteraciones.

Estudio de conducción nerviosa motora de las cuatro extremidades: se evidencian signos de compromiso axonal y mielínico de nervios periféricos. Estos hallazgos son compatibles con polineurorradiculopatía sensitivo motora.

Tabla 3. Punción lumbar 2

\section{Citoquímico de LCR}

Color antes de centrifugar

Incoloro

Aspecto antes de centrifugar

Transparente

Color después de centrifugar

Incoloro

Aspecto después de centrifugar

Transparente

$\mathrm{pH}$

8,0

Presencia de coágulo

No

\section{Examen citológico}

Recuento total de leucocitos

No se observan

Linfocitos

Neutrófilos $0 \%$

$0 \%$

Eritrocitos

$0 \%$

Recuento total

No se observan

Hematíes frescos

$0 \%$

Hematíes crenados

$0 \%$

\section{Examen químico}

Glucosa

$46 \mathrm{mg} / \mathrm{dl}$

Proteínas

$129,61 \mathrm{mg} / \mathrm{dl}$

$\mathrm{LDH}$

Otros

gérmenes.

Baciloscopia, $\mathrm{KOH}$, tinta china, Negativos VDRL, cultivo de LCR

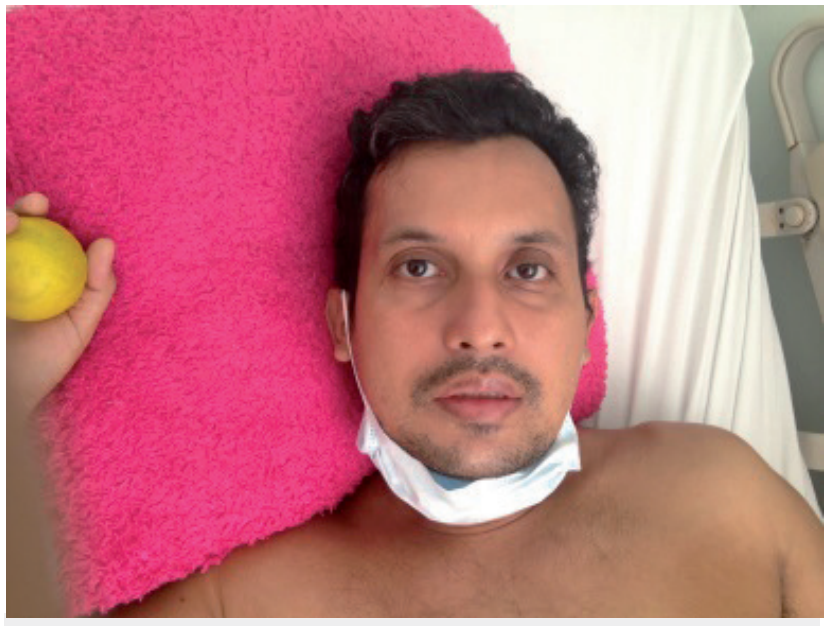

Figura 3. Octavo día pos-IGIV

Nota: se observa ligera mejoría de músculos faciales. Esta vez se insinúan los dientes al tratar de sonreír.

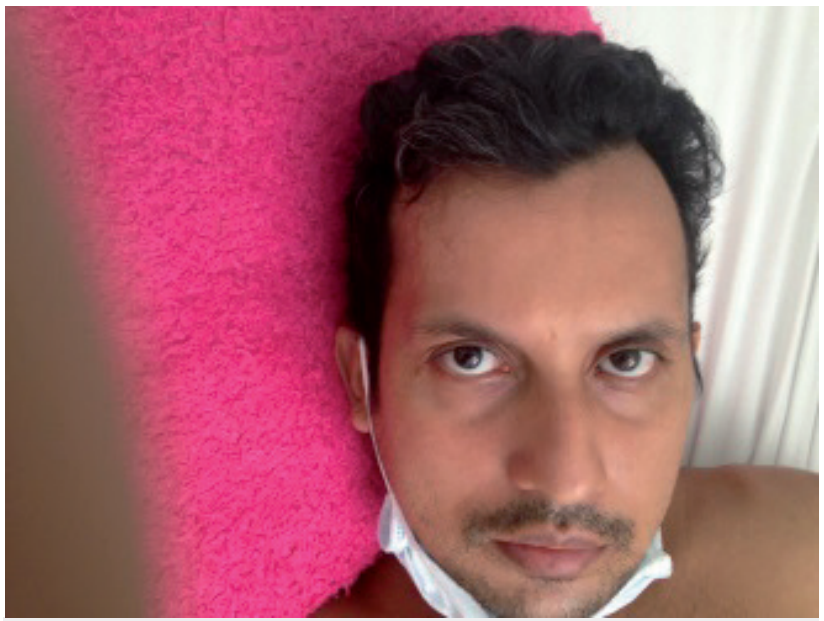

Figura 4. Octavo día pos-IGIV

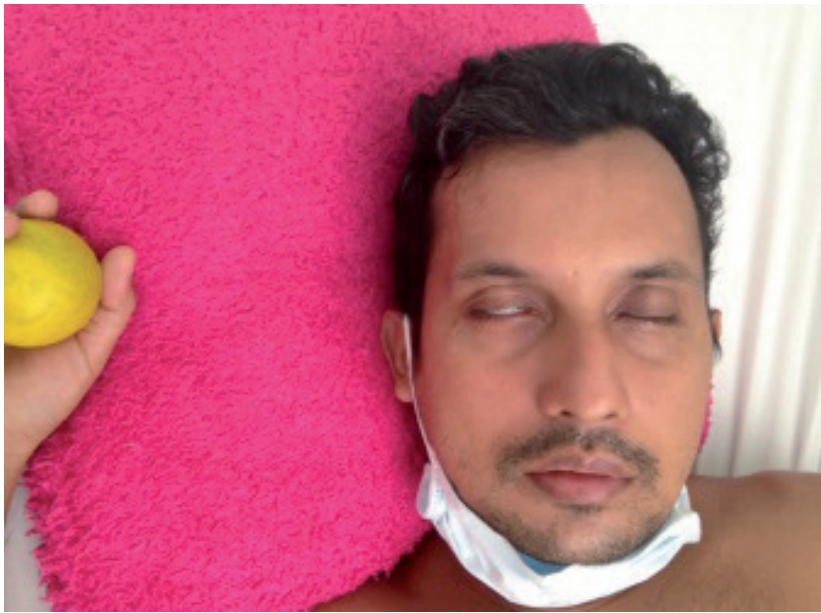

Figura 5. Octavo día pos-IGIV

Nota: se observa mejoría notoria de músculos palpebrales y signo de Bell unilateral derecho. 
afecta entre 23-25 pacientes por cada 100.000 individuos (11), la parálisis facial periférica bilateral es una manifestación neurológica rara, ocurre entre el 0,3-2\% de los pacientes (2) y puede tener diversas causas (1), entre las que se destacan infecciones como las causadas por citomegalovirus, virus de Epstein-Barr, Treponema pallidum, Mycoplasmapneumoniae, enfermedad de Lyme, enfermedades metabólicas tales como diabetes mellitus, neuropatías múltiples de los pares craneales, encefalitis del tallo cerebral, etcétera (5).

Generalmente, cuando una parálisis facial periférica bilateral es identificada en el examen físico está asociada como manifestación sistémica de una enfermedad potencialmente letal, por lo cual siempre debe hacerse un estudio extenso del paciente para tratar de determinar la causa (6). Cuando se presenta una parálisis facial periférica bilateral el síndrome de Guillian-Barré contribuye en más del 50\% de los casos $(6,12)$, aunque no es habitual que su forma de presentación inicial sea parálisis facial bilateral sin otra focalidad neurológica $(8,12)$.

El síndrome de Guillain-Barré es un grupo heterogéneo de polineurorradiculopatías agudas, de carácter inflamatorio y de origen inmunológico, descrito inicialmente por Jean Baptiste Octave Landry en 1859 como una "parálisis ascendente de las extremidades inferiores" con posterior compromiso de los músculos respiratorios. Este síndrome presenta varias formas de presentación clínica $(2,6,13)$, entre las que se destacan la neuropatía axonal motora aguda (AMAN), la neuropatía axonal sensitivo-motora (Asman) y el síndrome de Fisher-Miller; sin embargo, puede debutar con parálisis facial en $27-50 \%$ de los casos, a menudo bilateral (8). Cuando este fenómeno se presenta la parálisis facial usualmente es posterior a la debilidad muscular de las extremidades (9). Nuestro paciente debutó con parálisis facial días antes de la debilidad muscular de extremidades y de la arreflexia, lo que ha sido descrito como una "variante descendente" del síndrome de Guillain-Barré (14).

El diagnóstico del síndrome de Guillain-Barré inicia con la sospecha clínica $(2,6)$, seguida de la aplicación de los criterios diagnósticos propuestos por el Instituto Nacional de Desórdenes Neurológicos y Apoplejía (NINDS, por su sigla en inglés) y el Grupo de Clasificación de Síndrome de Guillain-Barré (GBSCG, por su sigla en inglés) (6, 10, 15), en que se destacan como criterios mayores la debilidad progresiva de brazos y piernas junto con arreflexia osteotendinosa. No obstante, cabe recordar que hasta el 10\% de los pacientes con Guillain-Barré presentarán reflejos osteotendinosos dentro de la normalidad, o aumentados $(12,13)$. Manifestaciones que respaldan el diagnóstico son: progresión de síntomas entre un día y cuatro semanas, simetría de síntomas, leves síntomas sensitivos, disfunción autonómica, afección bilateral de pares craneales, concentración elevada de proteínas en el líquido cefalorraquídeo con menos de $10 \times 10^{6}$ células/L (cambios que empiezan a aparecer durante la primera semana y alcanzan su pico máximo entre dos y cuatro semanas).

En nuestro paciente la disfunción autonómica estuvo dada por fluctuaciones en la tensión arterial y la frecuencia cardiaca. El patrón de evolución clásica del LCR, disociación albúmino-citológica, sólo se notó en la segunda punción lumbar que se realizó después de la primera semana.Finalmente, características electrodiagnósticas típicas, entre las que se destacan la ausencia del reflejo $\mathrm{H}$ y la onda $\mathrm{F}$ como las anormalidades más precoces en detectarse (7). Más adelante se detectaron los signos de desmielinización segmentaria como reducción de la velocidad de conducción, dispersión de respuestas evocadas, mayor latencia distal y reducción desproporcionada de la onda $\mathrm{F}(2,7)$. Imágenes como TC cerebral y RMN de cerebro o de columna deberían realizarse en el contexto adecuado solo como ayudas para el diagnóstico diferencial $(2,8)$.

Otra clave diagnóstica en este paciente fue la ocurrencia de un cuadro presuntamente viral 20 días antes del cuadro clínico. Este hallazgo es consistente con el hecho de que en el 75\% de los casos el síndrome de Guillain-Barré está precedido de una infección respiratoria viral, aunque se han descrito casos después de enfermedad diarreica aguda por Campylobacter jejuni $(2,6,13)$.

Después de instaurada la cuadriparesia flácida el paciente presentó "test de respiración única" positivo, por lo que fue trasladado a unidad de cuidados intermedios por el riesgo de falla respiratoria. En este contexto es necesario tener en cuenta que una vez se haya hecho el diagnóstico clínico hay que evaluar de inmediato criterios de ventilación mecánica $(13,16)$ y por ende de ingreso a unidad de cuidados intensivos (Tabla 4). Una forma "burda" de evaluar la reserva respiratoria es con la "prueba de respiración única", en la cual se le pide al paciente que cuente ininterrumpidamente después de una inspiración profunda (17). Por lo general el paciente puede contar hasta 50 , pero cuando solo llega a 25 corresponde a una capacidad vital forzada (CVF) de más o menos $2 \mathrm{~L}$, y si llega hasta 10 , la CVF es de $1 \mathrm{~L}$, lo que representaría deterioro respiratorio inminente. Otro dato a tener en cuenta durante el examen físico es evaluar la fuerza de flexión del cuello mientras se ejerce resistencia. Si la "fuerza de flexión" está deprimida, refleja algún grado de debilidad diafragmático, puesto que comparten la misma inervación (18). La disfunción bulbar grave (déficit de pares craneales bajos, reflejos de tos y nauseoso) alteran negativamente la capacidad del paciente para proteger la vía aérea (18). El $25 \%$ de los pacientes presentan deterioro respiratorio y de estos el 65\% alguna complicación relacionada con la ventilación mecánica, tales como sepsis, neumonía, embolismo pulmonar y sangrado gastrointestinal $(2,13)$. 
Tabla 4. Criterios para ingreso a unidad de cuidados intensivos $(16,17)$

\begin{tabular}{ll} 
Clínicos & Laboratorio \\
\hline Agitación, ansiedad & Volumen corriente $<15 \mathrm{ml} / \mathrm{kg}$ \\
\hline Taquicardia, taquipnea & $\begin{array}{l}\text { Presión inspiratoria máxima } \\
<25 \mathrm{mmHg}\end{array}$ \\
\hline
\end{tabular}

Incapacidad de contar hasta

20 sin parar (test o prueba de

respiración única)

Uso de musculatura accesoria Acidosis respiratoria

Respiración paradojal

Nuestro paciente fue manejado inicialmente con dexametasona teniendo en cuenta el diagnóstico diferencial de encefalitis viral, pero después de hacerse el diagnóstico de síndrome de Gullain-Barré se inició manejo con inmunoglobulina humana intravenosa, mostrando una respuesta favorable. Los corticoides no han denotado utilidad en el manejo de los pacientes con Guillain-Barré $(6,13,18)$. Se ha utilizado la inmunoglobulina humana intravenosa y la plasmaféresis como medidas igualmente eficaces para el control y manejo de esta entidad $(2,6,8,13)$; tienen su mayor eficacia durante la primera semana de haber iniciado el cuadro, aunque se cuestiona su uso después de la segunda semana de comenzar los síntomas debido a la poca utilidad en este tipo de pacientes. Las dosis de inmunoglobulina humana (IGIV) utilizadas son de $400 \mathrm{mg} / \mathrm{kg} /$ día durante cinco días consecutivos $(2,6,7,19)$. Actualmente en la mayoría de los centros se prefiere el uso de inmunoglobulina humana debido a su fácil consecución (18) y el ser menos costosa (13). La combinación de plasmaféresis y la inmunoglobulina humana intravenosa no ofrece beneficios aditivos (19). El paciente respondió de manera favorable desde el egreso y la mejoría fue sostenida dentro de los doce meses de seguimiento, fenómeno consistente con la evolución observada en casos similares informados en la literatura $(8,12)$.

\section{CONCLUSIÓN}

La parálisis facial periférica bilateral es una entidad neurológica rara que generalmente se asocia al síndrome de Guillain-Barré. Es necesario hacer el diagnóstico diferencial con otras entidades clínicas que cursan con parálisis facial periférica bilateral. El manejo es de soporte e idealmente debe realizarse en un sitio que disponga de monitoría cardiaca y respiratoria permanente. Se debe iniciar IGIV en el menor tiempo posible para aumentar la probabilidad de recuperación en este tipo de pacientes. El pronóstico es bueno en la mayoría de los casos.

\section{Conflicto de intereses}

Los autores declaran no tener conflicto de intereses.

\section{REFERENCIAS}

1. PEITERSEN E. Bell's palsy: the spontaneous course of 2,500 peripheral facial nerve palsies of different etiologies. Acta OtoLaryngologica 2002;122(7):4-30.

2. VAN DEN BERG B, WALGAARD C, DRENTHEN J, FOKKE C, JACOBS BC, VAN DOORN PA. Guillain-Barre syndrome: pathogenesis, diagnosis, treatment and prognosis. Nature Reviews Neurology 2014;10(8):469-82.

3. HUGHES RA, CORNBLATH DR. Guillain-Barré syndrome. The Lancet 2005;366(9497):1653-66.

4. CALLEJO FG, VILA MV, MATEU LP, CAÑIZARES J, ALGARRA JM. Parálisis facial periférica bilateral y síndrome de Guillain-Barré. Acta Otorrinolaringol Esp. 1998;49:561-7.

5. WINER J. An update in Guillain-barré syndrome. Autoimmune diseases 2014;2014.

6. VRIESENDORP F. Clinical features and diagnosis of GuillainBarre syndrome in adults; 2011.

7. LEHMANN HC, HUGHES RA, KIESEIER BC, HARTUNG HP. Recent developments and future directions in Guillain-Barré syndrome. Journal of the Peripheral Nervous System 2012;17(s3):57-70.

8. RIPOLL GP, PELLICER PL, DE LA PUERTA GONZÁLEZMIRÓ I, JUSTE CT, MARTÍNEZ CÍ, ET AL., Eds. Diplejia facial: variante regional del síndrome de Guillian-Barré. Anales de medicina interna. España: SciELO; 2007.
9. ASBURY AK, CORNBLATH DR. Assessment of current diagnostic criteria for Guillain-Barré syndrome. Annals of neurology 1990;27(S1):S21-S24.

10. BELL C. The nervous system of the human body. Archives of Neurology 1969;21(6):662-6.

11. PITTS DB, ADOUR KK, HILSINGER RL. Recurrent Bell's palsy: analysis of 140 patients. The Laryngoscope 1988;98(5):535-40.

12. WAKERLEY BR, YUKI N. Mimics and chameleons in Guillain-Barré and Miller Fisher syndromes. Practical neurology 2014:practneurol-2014-000937.

13. YUKI N, HARTUNG H-P. Guillain-Barré syndrome. New England Journal of Medicine 2012;366(24):2294-304.

14. NARAYANAN RP, JAMES N, RAMACHANDRAN K, JARAMILLO MJ. Guillain-Barré Syndrome presenting with bilateral facial nerve paralysis: a case report. Cases J. 2008;1(1):379.

15. WAKERLEY BR, UNCINI A, YUKI N. Guillain-Barre and Miller Fisher syndromes [mdash] new diagnostic classification. Nature Reviews Neurology 2014;10(9):537-44.

16. AWAN MI. CLINICAL PREDICTORS OF MECHANICAL VENTILATION IN GUILLAIN-BARRÉ SYNDROME (GBS). Pakistan Journal of Neurological Sciences 2014;9(2). 
17. PAUL BS, BHATIA R, PRASAD K, PADMA M, TRIPATHI $\mathrm{M}$, SINGH M. Clinical predictors of mechanical ventilation in Guillain-Barré syndrome. Neurology India 2012;60(2):150.

18. ANSAR V, VALADI N. Guillain-Barré Syndrome. Primary Care: Clinics in Office Practice 2015;42(2):189-93.

19. VAN DEN BERGH PY, HADDEN RD, BOUCHE P,
CORNBLATH DR, HAHN A, ILLA I, ET AL. European Federation of Neurological Societies/Peripheral Nerve Society guideline on management of chronic inflammatory demyelinating polyradiculoneuropathy: report of a joint task force of the European Federation of Neurological Societies and the Peripheral Nerve Society - first revision. European Journal of Neurology 2010;17(3):356-63. 